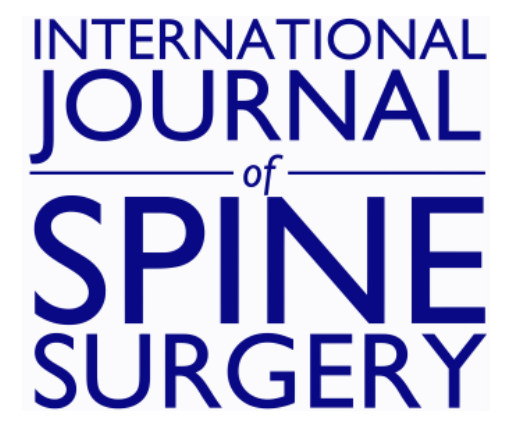

\title{
How Much Work Effort is Involved in Minimally Invasive Sacroiliac Joint Fusion?
}

Tara Garber, Charles G.T. Ledonio and David W. Polly, Jr

Int J Spine Surg 2015, 9 ()

doi: https://doi.org/10.14444/2058

http://ijssurgery.com/content/9/58

This information is current as of April 26, 2023.

Email Alerts Receive free email-alerts when new articles cite this article. Sign up at:

http://ijssurgery.com/alerts

The International Journal of Shing Surgerih 2397 Waterbury Circle, Suite 1,

Aurora, IL 60504, Phone: +1-630-375-1432

(C) 2015 ISASS. All Rights Reserved. 


\section{How Much Work Effort is Involved in Minimally Invasive Sacroiliac Joint Fusion?}

Tara Garber, PA-C, Charles G.T. Ledonio, MD, David W. Polly, Jr., MD

Department of Orthopaedic Surgery, University of Minnesota

\section{Abstract}

Background

Minimally invasive sacroiliac joint fusion is increasing significantly. Starting January 1, 2015, it has a category I

CPT code. The current RVU for this procedure is not equal to the amount of work involved. There is not a published RUC validated survey to establish the work effort of MI SI fusion. Our hospital system has been doing this procedure for 4 years and has been tracking surgeon time through a commercial tracking system (Navicare). Our study looks at time utilization for performance of MI SI joint fusion and a comparator of primary lumbar discectomy (PLD), presumably similar in time and work effort.

\section{Methods}

This study was a retrospective review of prospectively collected data using Navicare. The data for 3 surgeons who perform MI SI joint fusion and lumbar discectomies from January 1, 2013 through November 30, 2014 was retrieved. Surgeon room time was identified as the time the patient entered the OR to the time they exited the OR. This was used as opposed to skin to skin time seen in similar studies as it was more accurately and consistently recorded in the medical record. Mean and standard deviations were then compared using student's t-test.

Results

In 50 primary MI SI joint fusions, the average in-room time was 112 minutes (SD=23). In 89 cases of PLD, the average in-room time was 119 minutes $(\mathrm{SD}=26)$. When comparing mean in-room times, MI SI and PLD were not statistically significantly different ( $\mathrm{p}=0.135,2$-tailed $\mathrm{t}$-test). Post-operative work effort was found to be greater for MI SI joint fusion than PLD.

\section{Conclusions / Level of evidence}

Surgical time was found to be comparable between MI SI joint fusion and PLD, while work effort was found to be greater for MI SI joint fusion. This signifies at a minimum an equal RVU for PLD should be used for MI SI joint fusion. This study was approved by the Institutional Review Board at the University of Minnesota. Level of evidence: 3 .

KEYWORDS: WORK EFFORT, SACROILIAC FUSION, MINIMALLY INVASIVE, MIS, SIJ

VOLUME 9 ARTICLE 58 DOI: 10.14444/2058

\section{Introduction}

Sacroiliac (SI) joint pain accounts for $15-25 \%$ of all low back pain. ${ }^{1}$ Diagnosis is typically based on a combination of medical history, structured physical examination, provocative maneuvers, preclusive imaging studies, and confirmatory intra-articular joint injections. First-line therapies for SI joint pain are conservative, and include pain medication, manipulative therapy, physical therapy, therapeutic injections, and perhaps a pelvic compression belt. When nonoperative intervention repeatedly fails, fusion of the
SI joint is considered.

The frequency of SI joint fusion has been increasing with the availability of new minimally invasive (MI) surgical techniques, ${ }^{2}$ which offer clear and significant advantages over open surgical approaches. ${ }^{3}$ Initially, all SI joint fusions were assigned the current procedural technology $\left(\mathrm{CPT}^{\circledast}\right)$ code 27280 , and this code may still be employed on the recommendation of payers at their discretion. When a North American Spine Society (NASS) American Medical Association (AMA) CPT committee member suggested that 
the minimally invasive surgical approaches to MI SI fusion had different work efforts than the open cases, a temporary category III or " $\mathrm{T}$ " code was assigned, $0334 \mathrm{~T}$. This resulted in many payers denying the procedure. Given the developing published data, the AMA CPT committee has subsequently approved a new category I code for MI SI fusion, 27279, which went into effect on January $1,2015 .^{4}$

Assigning a relative value unit (RVU) to the new code proved difficult. An RVU committee found a dearth of valid work effort survey work, so selected the benchmark comparator of percutaneous discectomy (CPT 62287), which has a work RVU of 9.03 (Table 1). In our experience, this RVU is insufficient to encompass the work effort of MI SI joint fusion. This study seeks to examine and define the surgical or intra-service work effort of MI SI joint fusion, and to assess this work effort against the benchmark comparator of open percutaneous lumbar microdiscectomy (PLD) (CPT “microdisc”) (RVU 13.18), using intra-service work effort data collected among three surgeons who have performed multiple lumbar microdiscectomies and MI SI joint fusions at the same institution.

\section{Methods}

This study was a retrospective review of prospectively collected data using a hospital based operating room time management system, Navicare ${ }^{\circledast}$ (TeleTracking Technologies, Pittsburgh, PA). This study was reviewed by our Institutional Review Board, and was granted approval as category 5 research. Approval was received for access to 150 records from

Table 1. Current RVUs per the physician fee schedule for pertinent
procedures.
\begin{tabular}{|l|r|r|r|r|r|}
\hline Procedure Name & $\begin{array}{r}\text { CPT } \\
\text { Code }\end{array}$ & $\begin{array}{r}\text { Work } \\
\text { RVU }\end{array}$ & $\begin{array}{r}\text { Practice } \\
\text { expense } \\
\text { RVU }\end{array}$ & $\begin{array}{r}\text { Malpractice } \\
\text { RVU }\end{array}$ & $\begin{array}{r}\text { Total } \\
\text { RVU }\end{array}$ \\
\hline $\begin{array}{l}\text { Posterior lumbar mi- } \\
\text { crodiscectomy }\end{array}$ & 63030 & 13.18 & 10.95 & 4.16 & 28.29 \\
\hline Percutaneous discectomy & 62287 & 9.03 & 6.35 & 1.14 & 16.52 \\
\hline Open SI fusion & 27280 & 14.64 & 12.29 & 4.22 & 31.15 \\
\hline MI SI fusion & 27279 & 9.03 & 5.88 & 1.14 & 16.05 \\
\hline
\end{tabular}

CPT: current procedural technology; RVU: relative value unit; SI: sacroiliac; MI: minimally invasive. http://www.cms.gov/apps/physician-fee-schedule/ Accessed 06/26/2015
Fairview Health Services with a waived requirement of informed consent as research involves no more than minimal risk to subjects. Case logs for 3 surgeons who perform MI SI joint fusion and PLDs from January 1, 2013 through November 30, 2014 were reviewed by an independent observer who identified all primary MI SI joint fusions and primary PLDs via electronic medical record review, and all patient identifying information was removed from the working dataset. Surgeon room time was calculated as the elapsed time from patient operating room entry to exit. This duration was preferred over skinto-skin time, as it was felt to be more accurately recorded in the medical record at our institution. Data was entered into an Excel spreadsheet (Microsoft, Seattle, WA). Mean and standard deviations were calculated using built-in functionality of the Excel program. These were then compared between PLD and MI SI joint fusion using student t-test. Patient records were analyzed to determine length of hospital stay, and this was entered into an Excel spreadsheet. Mean and standard deviations were calculated. Using physician estimates, we then compared the physician work effort involved pre-, intra-, and postoperatively for patient care for both procedures.

\section{Results}

There were 50 primary MI SI joint fusions; 37 (73\%) were female and 13 (27\%) male, with a mean age of 52 years $(\mathrm{SD}=13)$. The average in-room time was 112 minutes ( $\mathrm{SD}=23)$. There were 89 cases of PLD; 39 (44\%) were female and 50 (56\%) male, with a mean age of 46 years $(\mathrm{SD}=15)$. The average in-room time was 119 minutes $(\mathrm{SD}=26)$ (Figure 1). In comparing mean in-room times, MI SI and PLD were not statistically significantly different $(\mathrm{p}=0.135,2$-tailed $\mathrm{t}$ test). 50/50 (100\%) MI SI joint fusion patients were admitted postoperatively. PLD patients were admitted due to complications including dural tear (4/12), urinary retention $(1 / 12)$, pain $(5 / 12)$, and breathing issues $(2 / 12)$ for a total of $12 / 89$ (13\%) (Figure 2). This was comparable to complication rates seen in the literature. ${ }^{5-7}$

\section{Discussion}

We found that intraoperative time is similar between 
MI SI joint fusion and PLD. Work effort was found to be greater for MI SI joint fusion than PLD. There is a well-recognized, well accepted RVU for open PLD and at a minimum MI SI joint fusion has equivalent work effort.

Preoperatively, more work effort is spent for painful sacroiliac joint disease. A thorough diagnostic work up includes multiple clinic appointments to rule out lumbar and hip pathology, put the patient through several provocative maneuvers, and pelvic imaging to accurately diagnose the disorder. After the preliminary diagnosis is made, time is spent arranging preoperative injections and physical therapy with further follow up appointments to discuss response to these interventions. Determining a patient's response is purely based on subjective feedback, and good response to these interventions does not guarantee a patient will respond well to surgery, making thorough history and physical exam vital to patient selection for surgical intervention. More work effort is spent on securing prior authorization for coverage of the procedure compared to PLD. MI SI joint fusion required prior authorization approval for essen-

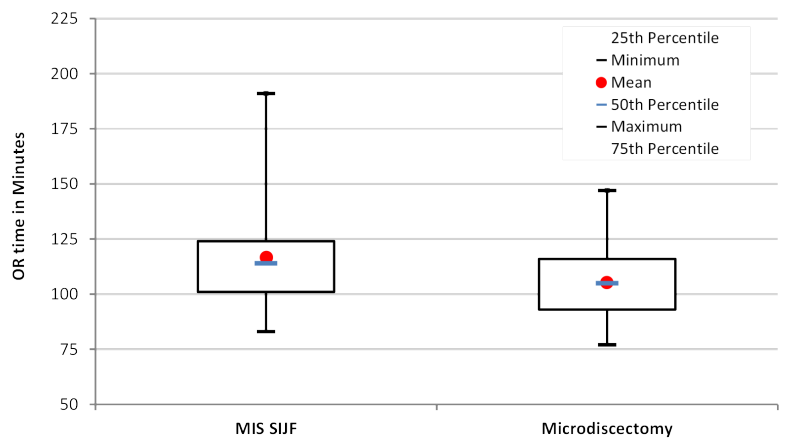

Fig. 1. Operating Room Time. This represents in-room to out-of-room time for MI SI joint fusion and PLD.

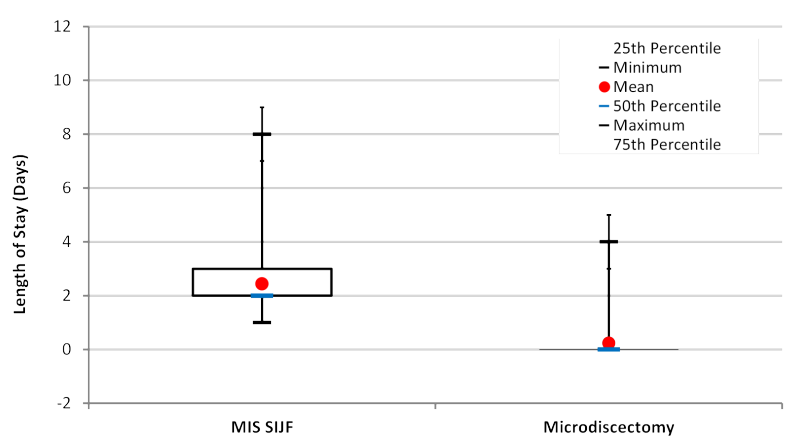

Fig. 2. Length of Stay. All MI SI joint fusion patients were admitted. Only $13.5 \%$ of PLD patients were admitted. tially all of our commercial and government payers, including workers compensation; the estimate of this back office work time was approximately 7-8 hours per our back office surgery prior authorization / scheduler. The physicians estimated an average of 15-30 minutes to explain prior authorization to patients, and it took an average of 10-20 minutes of physician time to prepare appeals correspondence. Although similar effort is involved with counseling and surgical scheduling for both procedures, MI SI procedures require added time for implant vendor coordination. PLD requires a physical exam and MRI of the lumbar spine to correlate. Typically transforaminal epidural steroid injections are ordered and patients are managed conservatively for at least 6 weeks prior to surgical intervention. In the vast majority of these cases there is little doubt about the diagnosis.

Intra-operatively, more cognitive effort is required for MI SI joint fusion than PLD. MI SI joint fusion is an additional skill set that not all spine surgeons possess, requiring work effort and judgment for placement of instrumentation based upon intra-operative imaging. PLD is a common procedure done by most spine surgeons, and it requires level identification, nerve root and dural sac identification and manipulation, but no instrumentation is placed during the procedure. Imaging occurs throughout the procedure for MI SI joint fusion, with an intraoperative CT scan and multiple pelvic inlet, outlet, and lateral views. In two prospective studies registered at clinicaltrials.gov, fluoroscopy times were available to us. ${ }^{8,9}$ For the SIFI clinical trial with 172 patients the mean fluoro time was 2.7 minutes (range $0.3-14$ ), and for the INSITE study there were 102 patients with a mean fluoro time of 2.5 minutes (range $0.13-25$ ). PLD requires minimal fluoroscopic exposure to determine levels, typically 1-3 fluoro shots.

Our data showed that MI SI joint fusion and PLD intraoperative times were similar (112 and 119 minutes, respectively).

Postoperatively, discectomy patients are typically discharged same day absent any complications requiring further intervention or observation. In our patient cohort, complications or other medical con- 
ditions requiring observation or admission were seen in 12 of 89 patients (13.5\%) (Table 2). Comparable complication rates are seen throughout the literature with variance based on surgeon experience. ${ }^{5-7}$ MI SI joint fusion patients are typically admitted for several days, with added physician time spent rounding daily, managing care, and interpreting radiographs. Activity is limited for the MI SI joint fusion patients as they are toe touch weight bearing on crutches for the first 3-6 weeks postoperatively. Physical therapy is consulted during their hospital stay to teach proper crutch walking and minimal weight bearing. For post-procedure care, the MI SI joint fusion patients had an average length of stay of $3.5 \pm 2.12$ days. Only 12/89 PLD patients were admitted, so even with similar ward management the work effort required for MI SI joint fusion and TLIF exceeded PLD due to $100 \%$ admission compared to $13 \%$, respectively.

At this time, reimbursement for MI SI joint fusion is equivalent to a percutaneous discectomy with an RVU of 9.03. This study shows the actual amount of work involved for this procedure is greater than an open PLD which has an RVU value of 13.18. RVUs are determined by the time it takes to provide a service and the relative intensity of providing that service. Intensity is determined by technical skill, physical effort, mental effort and judgement, and stress involved in providing the service..$^{10}$ Our findings suggest that at a minimum the physician work and effort for MI SI joint fusion should be at least that of PLD and probably more. We also found that MI SI procedures have greater post-operative work efforts than PLD, with average length of hospital stay approximately 3 days longer than PLD requiring post-op care. One hundred percent of MI SI joint fusion patients were admitted, while only $13.5 \%$ of PLD patients were admitted. With the similarities between intraoperative time and effort, and even increased effort required for MI SI joint fusion, the PLD RVU appears to be a minimum benchmark for MI SI joint

Table 2. Postoperative admission frequency and duration.

\begin{tabular}{|l|r|r|r|r|}
\hline Procedure & $\begin{array}{r}\text { Number of } \\
\text { cases }\end{array}$ & $\begin{array}{r}\text { In-room time } \\
\text { (minutes) }\end{array}$ & $\begin{array}{r}\text { Admitted } \\
\text { patients }\end{array}$ & $\begin{array}{r}\text { Length of } \\
\text { stay (days) }\end{array}$ \\
\hline $\begin{array}{l}\text { MI SI joint } \\
\text { fusion }\end{array}$ & 50 & $112 \pm 23$ & 50 & $3.5 \pm 2.12$ \\
\hline PLD & 89 & $119 \pm 26$ & 12 & $0.34 \pm 0.99$ \\
\hline MI: minimally invasive. SI: sacroiliac; PLD: primary lumbar discectomy.
\end{tabular}

fusion but may well underestimate the pre- and postprocedure work effort.

Currently the 90-day global period covers the physician work for post-procedure care. It is the impression of the authors that there is more work associated with direct care for the MI SI joint fusion patients compared to the PLD patients. MI SI patients are toe touch weight bearing on crutches for 3 weeks postoperatively. We have observed that this commonly results in quadratus lumborum spasms, causing return of pain after the patients initially improve, which in turn may drive MI SI patients to seek an extra clinic visit for assessment and management. We now train MI SI patients to stretch their quadratus lumborum pre-operatively, which has decreased but not eliminated these visits. MI SI patients universally receive supervised PT to return to normal gait. Physical therapy is common but not universal in our PLD patients. Post-operative imaging is also routine at each visit for our MI SI patients. This is done to assess the stability of the fusion and/or fixation. We have seen loosening about some implants in patients. This has correlated with return of symptoms in a number of patients and we believe that this radiographic surveillance is merited for best care. PLD patients do not require routine imaging at follow up appointments.

\section{Conclusion}

We found that surgical time (defined as elapsed room time) for MI SI joint fusion was statistically equivalent to PLD. MI SI joint fusion in room time is 112 minutes, similar to PLD with work RVU 13.18 (per Medicare fee schedule). Work effort, however, is greater for MI SI joint fusion. This is a useful data set to understand the relative intra-service work of MI SI joint fusion and allocate an optimal relative value unit.

\section{References}

1. Sembrano JN, Polly DW, Jr. How often is low back pain not coming from the back? Spine (Phila $\mathrm{Pa}$ 1976). 2009;34(1):E27-32.

2. Lorio MP, Polly DW, Jr., Ninkovic I, Ledonio

Downloaded from http://ijssurgery.com/ by guest on April 26, 2023 
CG, Hallas K, Andersson G. Utilization of minimally invasive surgical approach for iacroiliac joint fusion in surgeon population of ISASS and SMISS membership. Open Orthop J. 2014;8:1-6.

3. Smith AG, Capobianco R, Cher D, et al. Open versus minimally invasive sacroiliac joint fusion: $A$ multi-center comparison of perioperative measures and clinical outcomes. Ann Surg Innov Res.

2013;7(1):14.

4. AMA. Rationale. $C P T^{\circledast}$ Changes 2015: An Insider's View: American Medical Association Press;

2015:39-40.

5. Tafazal $S$, Sell P. Incidental durotomy in lumbar spine surgery: Incidence and management. Eur Spine J. 2005;14(3):287-290.

6. Morgan-Hough CVJ, Jones PW, Eisenstein SM. Primary and revision lumbar discectomy: A 16-year review from one centre. J Bone Joint Surg Br. 2003;85-B(6):871-874.

7. Wiese M, Krämer J, Bernsmann K, Ernst Willburger $\mathrm{R}$. The related outcome and complication rate in primary lumbar microscopic disc surgery depending on the surgeon's experience: Comparative studies. Spine J. 2004;4(5):550-556.

8. Duhon B, Cher D, Wine K, Kovalsky D, Lockstadt $\mathrm{H}$. Triangular titanium implants for minimally invasive sacroiliac joint fusion: A prospective study. Global Spine J.Epub Aug 11 2015. DOI: 10.1055/ s-0035-1562912.

9. Polly DW, Cher DJ, Wine KD, Whang PG, Frank
CJ, Harvey CF, Lockstadt H, Glaser JA, Limoni RP, Sembrano JN. Randomized controlled trial of minimally invasive sacroiliac joint fusion using triangular titanium implants vs nonsurgical management for sacroiliac joint dysfunction: 12-month outcomes. Neurosurgery. 2015;77(5):674-91.

10. Centers for Medicare and Medicaid Services. CMS-1612-FC - Addendum B. CY 2015 Relative Value Units and Related Information used in Determining Final Medicare Payments. http://www.cms.gov/ Medicare/Medicare-Fee-for-Service-Payment/ PhysicianFeeSched/PFS-Federal-RegulationNotices-Items/CMS-1612-FC.html. Accessed June 30, 2015.

\section{Disclosures}

The authors declare no relevant disclosures.

\section{Corresponding Author}

Tara Garber, Department of Orthopaedic Surgery, University of Minnesota, 2512 South 7th Street, Suite R200. tgarber11@umphysicians.umn.edu.

Published 6 November 2015.

This manuscript is generously published free of charge by ISASS, the International Society for the Advancement of Spine Surgery. Copyright $\odot 2015$ ISASS. To see more or order reprints or permissions, see http://ijssurgery.com. 